\title{
Mechanical and Morphological Characterization of Chitosan Scaffolds Produced by Particle Aggregation Method
}

\author{
Thiago B. Fideles ${ }^{1 *}$, Hugo M. Lisboa² ${ }^{2}$ Renata G. Araújo ${ }^{1}$, Luciane C. Trindade1, \\ Ítalo M. F. Pinheiro', Marcus V. L. Fook ${ }^{1}$ \\ ${ }^{1}$ Laboratory of Biomaterials Evaluation and Development-CERTBIO, Materials Engineering Department, \\ Campina Grande Federal University, Campina Grande, Brazil \\ ${ }^{2}$ Entro de Tecnologia e Recursos Naturais, Food Engineering Department, Campina Grande Federal University, \\ Campina Grande, Brazil \\ Email: *tfideles@gmail.com
}

How to cite this paper: Fideles, T.B., Lisboa, H.M., Araújo, R.G., Trindade, L.C., Pinheiro, Í.M.F. and Fook, M.V.L. (2017) Mechanical and Morphological Characterization of Chitosan Scaffolds Produced by Particle Aggregation Method. Open Access Library Journal, 4: e4021.

https://doi.org/10.4236/oalib.1104021

Received: October 12, 2017

Accepted: December 26, 2017

Published: December 29, 2017

Copyright $\odot 2017$ by authors and Open Access Library Inc.

This work is licensed under the Creative Commons Attribution International License (CC BY 4.0).

http://creativecommons.org/licenses/by/4.0/

\begin{abstract}
Development of novel biomaterials and its practical application have been the subject of much research in the field of scaffolds for tissue engineering, providing the success of producing scaffolds biomaterials that facilitate tissue growth and provide structure support for cells. The design and production of scaffolds for tissue engineering is yet unable to completely reproduce the native tissue properties. Preferably, scaffolds would be made of biodegradable polymers whose properties are more similar to the ECM. Chitosan, which is the copolymer of D-glucosamine and N-acetyl-D-glucosamine, is an excellent material due to its versatile properties and is one of the widely studied polymers for tissue engineering application. The objective of the present work was to characterize mechanical and morphological chitosan scaffolds produced by a particle aggregation method. Chitosan scaffolds were prepared throughout two steps: using the ionotropic gelation for macrosphere production and aggregation to produce the scaffolds. The chitosan scaffolds were characterized by Scanning Electron Microscopy (SEM) and Compression Tests. Through SEM results, was observed a three-dimensional structure, with $55 \%$ porosity and interconnectivity among pores. The pores were inhomogeneous and varied in the range of 40-262 $\mu \mathrm{m}$. The mechanical characterization by compression tests showed a very elastic and easily conformable structure, since the stress required to deform the scaffold is lower. The cytotoxicity results proved that the produced has no toxicity effects and cell viability values were enclose in $80 \%$.
\end{abstract}




\section{Subject Areas}

Bioengineering, Biological Materials

\section{Keywords}

Chitosan, Scaffolds, Aggregation Method, Biomedical Application

\section{Introduction}

The development of novel biomaterials and its practical application have been the subject of much research in the field of scaffolds for tissue engineering, providing the success of producing scaffolds biomaterials that facilitate tissue growth and provide structure support for cells and the delivery of bioactive molecules. The common concepts associated with tissue engineering research are based on the construction of hybrid materials obtained from the incorporation of cells into three-dimensional (3D) porous scaffolds. Scaffolds need to be developed for sustaining in vitro tissue reconstruction as well as for in vivo cell-mediated tissue regeneration. It is almost impossible to repair tissue defects if the cells are not supplied with some kinds of an Extracellular Matrix (ECM) structure [1] [2] [3].

Among the polymers classes, chitosan appears to be an excellent material due to its versatile properties. The past several decades have witnessed a rapid increase and maturation of applications based on a variety of polymeric biomaterials in the biomedical engineering field. The natural polysaccharide chitosan is one of many that has attracted much attention due to its natural origin, biocompatibility, enzymatic degradability, functionalization, antibacterial activity, and excellent processability [4] [5] [6] [7] [8].

Although chitosan processing technology is well known and often used by the manufactures, there are still some inconveniences that could be avoided in order to facilitate the production of chitosan-based materials. Almost know methods of scaffolds fabrication from chemically unmodified chitosan require prior dissolution of chitosan in an acidic medium such as acetic acid, the most commonly used. Standard scaffold fabrication procedures demand a step for residual acid removal from the final product, which is necessary because of the potentially harmful effects. This step is followed by additional drying of the scaffolds in order to obtain a dry final product. Such procedures often lead to the loss of the original structure as well as the partial dissolution of the scaffolds, rendering the procedure less reproducible [9]. Nevertheless, further research on the scaffold design is still needed because the chemical nature and structure of the $3 \mathrm{D}$ constructs significantly affect the success of tissue engineering approaches both in-vitro and in-vivo. Moreover, an optimal scaffold has not been identified yet.

Thereat, several different techniques and methodologies have been proposed to produce a variety of $3 \mathrm{D}$ naturally based scaffolds, suitable for tissue engineer- 
ing applications. In the past few years, there has been a trend toward the development of increasingly sophisticated scaffolds materials that may enable the combination of several functions within the same device [4] [10]. One innovative approach to designing polymer-based scaffolds is based in the micro and macrosphere technology. Recently, microspheres have also been assessed as scaffold for tissue engineering and new strategies have been investigated to obtain suitable scaffolds that mimic the tissue environment for cells [11].

The technique is generally based on the random packing of microspheres with further aggregation by physical or thermal means to create a three dimensional porous structure. This technique is being used to construct scaffolds directly or it can be proposed to be used indirectly by producing a negative structure which will serve as a reverse template to obtain the scaffolds. The porosity obtained in this type of scaffold can be easily controlled by the spheres diameter that will create the interstices when the particles are aggregated. If an increased pore size is desired, it is also possible to use macroparticles [12] [13] [14]. Jiang et al. reported the fabrication of a novel sintered microsphere scaffold based on synthetic polymer poly (lactide-co-glycolide) (PLAGA) and the polysaccharide chitosan [15]. Borden et al. developed a gel microsphere matrix and the sintered microsphere matrix were designed using the random packing of poly(lactide-coglycolide) microspheres to create a three-dimensional porous structure [16]. Kucharska et al. studies present a methodology of porous materials fabrication and the technique based on the agglomeration of polymer/composite microspheres in the presence of acetic acid solution in order to make the spheres adhere together and thus, led to the formation of 3D porous inner architecture [17]. Silva et al. produced chitin matrices with a random packing of the produced chitin beads and the chitin agglomerated scaffolds were built up by bonding microspheres using gellan gum as a glue to lead to stronger fusion of microspheres [18].

Hence, the aim of the present work was to produce and evaluate chitosan scaffolds produced by particle aggregation using gelatin as agglomeration agent as a potential material for biomedical applications.

\section{Materials and Methods}

\subsection{Materials}

Chitosan (medium molecular weight and deacetylation degree $\approx 75 \%-85 \%$ ), sodium tripolyphosphate (NaTPP), Gelatin from porcine skin and Phosphate Buffer Solution (PBS) were purchased from Sigma Aldrich, acetic acid $\left(\mathrm{CH}_{3} \mathrm{COOH}\right)$ was purchased from Vetec and used as received. All reagents were of analytical grade and were used without further purification.

Chitosan spheres preparation

Briefly, chitosan solutions were prepared by dissolving chitosan powder in a $1 \%(\mathrm{v} / \mathrm{v})$ acetic acid solution to form a final solution with a $2.0 \mathrm{wt} \%$ concentration. Afterwards, the solutions were filtered to remove insoluble residues. After 
complete dissolution and filtration, the prepared solutions were extruded through a syringe connected to a syringe pump at a constant rate $(25 \mathrm{ml} / \mathrm{h})$ to form chitosan spheres into a bath solution containing NaTPP solution (5\% wt) where spheres were produced.

Scaffolds preparation were fabricated using the porous chitosan scaffolds were produced according to Malafaya and co-workes using method previously described [10] [19]. The chitosan particles were collected and rinsed with PBS until neutral $\mathrm{pH}$, placed into cylindrical moulds, coated with Gelatin (5\% wt) and frozen at $-80^{\circ} \mathrm{C}$ for $24 \mathrm{~h}$. After, the frozen chitosan scaffolds were lyophilized for $48 \mathrm{~h}$ and submitted to characterization.

\subsection{Characterizations}

\subsubsection{Characterization of Spheres}

Lyophilized spheres were examined by a scanning electron microscope (model PHENOM PRO X) and the imaging was conducted at an accelerating voltage of $10 \mathrm{kV}$. Generated images were treated with analysis software Image $\mathrm{J}$ and at least 50 particles were examined to get average diameter and particle size distribution.

\subsubsection{SEM}

Chitosan spheres and chitosan scaffolds were morphologically characterized by scanning electron microscopy using an electron microscope model PHENOM $\mathrm{PRO} \mathrm{X}$ and generated images were treated with a 3D roughness analysis software and FIBERMETRIC (CERTBIO/UFCG). There was no need for further coating with gold particles, since it is low-voltage equipment.

Porosity and Pore Size Distribution

Different methods are proposed to assess the porosity of scaffolds and some authors use calculations from the density $(\rho)$ of chitosan, density and volume of manufactured scaffolds. Variation in porosity of the scaffold due to microspheres aggregation was determined using Hsieh et al. (2007) equation [14]:

$$
\begin{array}{r}
P(\%)=\frac{V_{m}-V_{P}}{V_{m}} \times 100 \\
P(\%)=\frac{V_{m-\left(w_{m} / \rho\right)}}{V_{m}} \times 100
\end{array}
$$

where:

$$
\begin{aligned}
& V_{m}=\text { Scaffolds Total Volume }\left(\mathrm{cm}^{3}\right) \\
& V_{P}=\text { Chitosan volume }\left(\mathrm{cm}^{3}\right) \\
& W_{m}=\text { Scaffolds mass }(\mathrm{g}) \\
& \rho=\text { Chitosan density }\left(0.3 \mathrm{~g} / \mathrm{cm}^{3} \text {-SIGMA ALDRICH }\right)
\end{aligned}
$$

The pore size distribution of microspheres was characterized following encapsulation by measuring the particle diameter in the SEM images using analysis software Image J. For each analysis, at least 50 pores were examined.

\subsubsection{Compression Tests}

Compression tests were performed by applying a compressive axial load using a 
universal electromechanical test machine (INSTRON model 3366) with a $500 \mathrm{~N}$ load cell on samples with a cylindrical shape with diameter/thickness ratio about 2 , with a constant deformation of $1.3 \mathrm{~mm} / \mathrm{min}$. The compressive strength was calculated by dividing the maximum load across and the original area. Three samples were tested and the average value of Young's modulus with their respective deviation was calculated for $10 \%$ of strain.

\subsubsection{Cytotoxicity}

The viability of cells grown on the scaffolds was determined using the colorimetric MTT assay. MTT assay measures the reduction of the tetrazolium component MTT by viable cells. Therefore, the level of reduction in MTT into formazan can reflect the level of cell metabolism. For the assay, was used the method of direct contact between the substrate material and the cells, according to ISO 10993-5 Standard. A cell line L929 was used on this assay. $100 \mu \mathrm{L}$ of a cell suspention at a density of $1 \times 10^{5}$ cells $/ \mathrm{ml}$ were dispensed into each well of a 96-well plate. $100 \mu \mathrm{L}$ of RPMI 1640-C (blank) were added to 12 wells. The plate was then incubated for 24 hours $\left(5 \% \mathrm{CO}_{2}, 37^{\circ} \mathrm{C}\right)$ so that an adherent and half-confluent cell monolayer is formed. After this time, the culture medium was aspirated and $200 \mu \mathrm{L}$ of fresh RPMI 1640-C were added to each well. The samples were then distributed through the wells, leaving 12 wells as negative control. The plate was incubated again for 24 hours $\left(5 \% \mathrm{CO}_{2}, 37^{\circ} \mathrm{C}\right) .100 \mu \mathrm{L}$ of a MTT solution $(1 \mathrm{mg} / \mathrm{ml})$ were added into each well and the plate was further incubated for three hours. The MTT solution was discarded and $100 \mu \mathrm{L}$ of Isopropanol were added in each well. The optical density was determined in a microplate reader (Victor3-PerkinElmer) at $540 \mathrm{~nm}$ with a reference filter of $620 \mathrm{~nm}$. Cell viability was calculated using the equation:

$$
\text { Viab } \%=\frac{100 \times \text { OD570e }}{\text { OD570b }}
$$

where OD570e is the mean value of the measured optical density of the test sample, and OD570b is the mean value of the measured optical density of the blanks.

\section{Results and Discussion}

\subsection{SEM}

The SEM results for chitosan spheres and chitosan scaffolds are shown in Figure 1. The chitosan spheres showed an elliptical shape and a rough surface with a microspheres average diameter of $1.9 \mathrm{~mm}$, with sizes ranging from 1.5 to 2.5 $\mathrm{mm}$ (Figure $1(\mathrm{c})$ ). Chitosan scaffolds possess a rough and higher porosity confirmed by SEM images of the surface. This type of surface was formed mainly due to the sublimation of frozen water crystals through lyophilization of scaffolds. It can see that the pores are interconnected in irregular patterns. The chitosan scaffolds were obtained with well-defined pore morphology (Figure 1(a) and Figure 1(b)). A structure with well-defined architecture of 


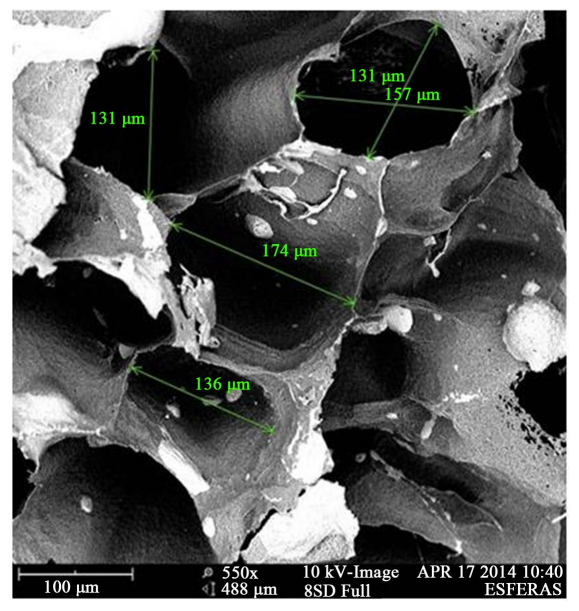

(a)

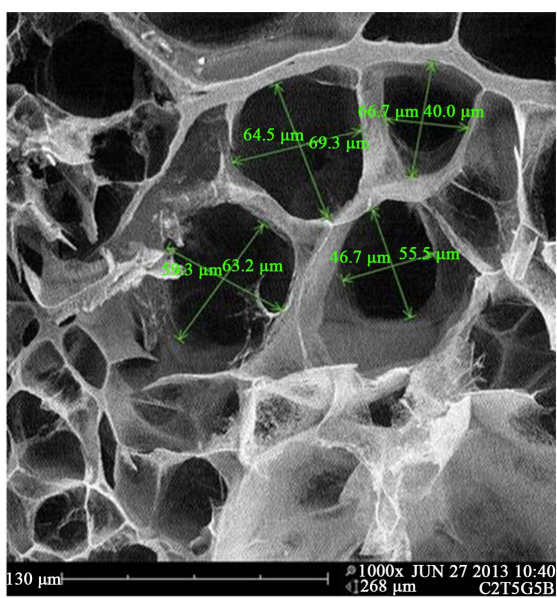

(b)

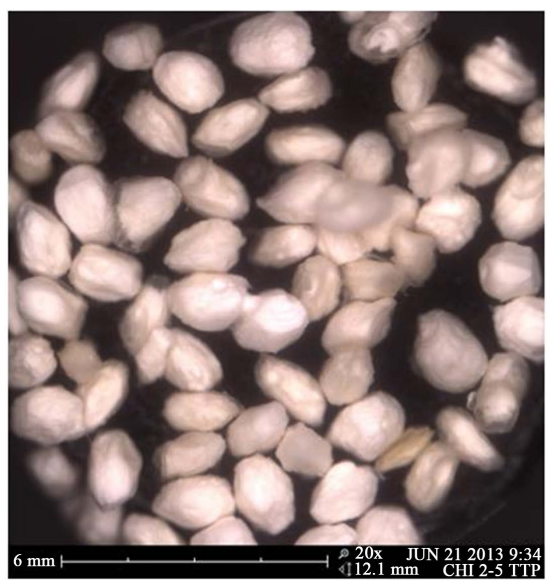

(c)

Figure 1. SEM of chitosan scaffolds microstructure (a) 550×; (b) $1000 \times$ and (c) $2000 \times$.

interconnected pores will facilitate a more uniform distribution of cells, nutrients and oxygen.

The porosity of scaffolds was estimated and according to the calculations, scaffolds showed an average porosity of 55\%. Kucharska et al. (2010) produced chitosan scaffolds by particle aggregation method and found values for average porosity of 40\% [20]. Malafaya et al. (2008) also produced scaffolds from chitosan particles by the same method and found average values for porosity of $28 \%$ [21]. For instance, the values of porosity of the scaffolds suggested that interconnected pores were formed in all structures, which may help in the cell penetration and nutrients diffusion, which will enhance the cellular activities in such structure.

Porosity and pore size distribution are important factors in the success of tissue engineering applications. Many studies have focused on the detection of optimal values for these factors. However, there are still contradictory results for the pore size distributions required for cell attachment and proliferation. In Figure 2, its showed the distributions of pore sizes for the scaffolds measured with the software ImageJ are given. 


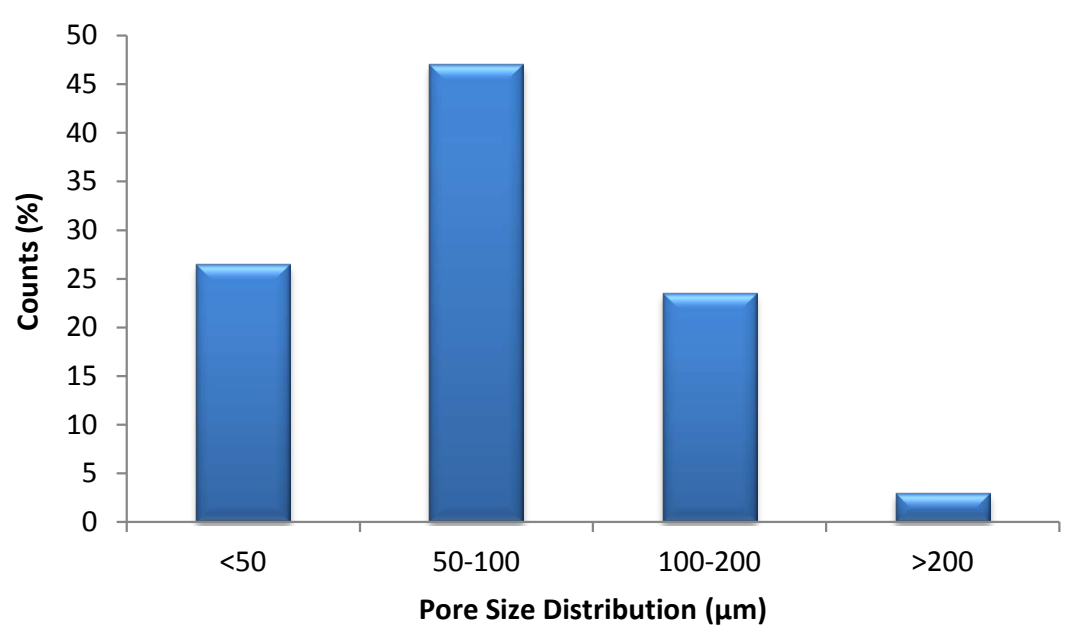

Figure 2. Pore size distribution of the chitosan scaffolds.

The pore size distribution results obtained from SEM images confirmed that the pores were inhomogeneous and varied in the range of $40-262 \mu \mathrm{m}$. From the plots, the size distribution of microsphere was found and there were four set of pores (average diameter $<50 \mu \mathrm{m}$, which is $26.5 \%$ of total abundance, $50-100$ $\mu \mathrm{m}$, which is $47.1 \%$ of total abundance, $100-200 \mu \mathrm{m}$, which is $23.5 \%$ of total abundance and $>200 \mu \mathrm{m}$ which is $2.9 \%$ of total abundance). These results indicated that chitosan scaffolds has a more open structure and these features could be of interest for cell adhesion onto produced scaffolds.

Jiang et al. developed chitosan/PLAGA sintered microsphere scaffold and the scaffolds has an approximate porosity of $30 \%$, median pore size of $170-200 \mu \mathrm{m}$ [15]. Silva et al. produced chitin beads and chitin hybrid beads. They results demonstrated that chitin beads has a closed structure when compared to chitin hybrid beads, which had influenced in the pore size. It was also observed that the obtained chitin beads showed different morphologies that varied from a smooth surface (chitin beads) to a rough surface (chitin hybrid beads) and chitin hybrid beads has a more open structure, where pores raging between 50 and $200 \mu \mathrm{m}$ [18]. Valente et al. produced an alginate based aggregated scaffolds and materials presented pores with diameter values above $1 \mu \mathrm{m}$ and the values of porosity determined were ranging from $6.661 \%$ to $6.907 \%$ for the scaffolds [22].

One drawback of microsphere scaffolds is the low level of overall porosity, where the variation of porosity, which lies between 40 and $60 \%$, compared to $>90 \%$ exhibited by scaffolds prepared via the phase separation technique, as reported on a previous work [3].

\subsection{Compression}

Compression tests were performed to generate the stress-strain curve and calculate the Young's modulus (E). The initial slope of the curve was used to calculate the modulus at $10 \%$ strain, since the curved elastic region showed a much lower stress value. Figure 3 shows the stress-strain curve of chitosan scaffolds/TPP. 


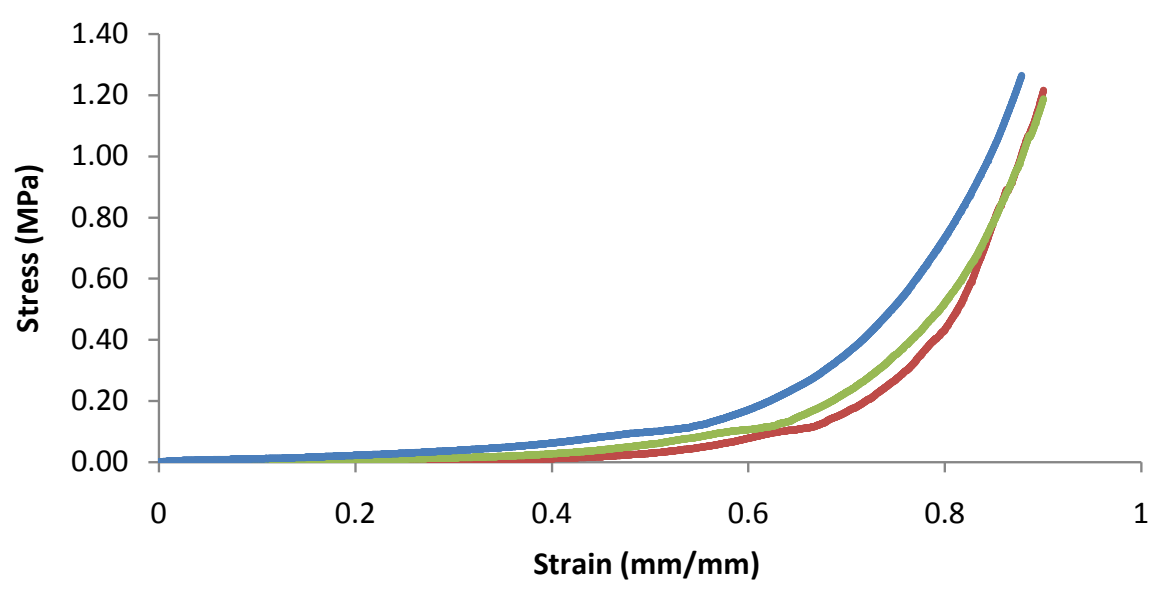

Figure 3. Stress-Strain curve for chitosan scaffolds.

The curves obtained show that the three scaffolds reveal similar characteristics to polymeric foams. The mean values for the Young's modulus (E) were 0.0529 $\mathrm{MPa}$, and indicate that scaffolds showed a very elastic and easily conformable structure, since the stress required to deform the scaffold is lower. It is known that chitosan is a semi-crystalline polymer and the low modulus and tension values can be attributed to the low degree of crystallinity, as described by Wan et al. (2008) [23]. Yao et al. (2012) produced chitosan scaffolds and found (E) $0.0387 \mathrm{MPa}$ modulus values [24]. Another factor that can influence the mechanical behavior of chitosan scaffolds is the degree of deacetylation (DD), which has influence on various properties of chitosan, including crystallinity, degradation and mechanical strength.

In the initial compression stage scaffolds showed low tensile strength, where identification of the linear elastic region is almost imperceptible. This linear region occurs due to elastic bending of the walls of the pores. After this, a long plateau can be observed revealing the compression of the pores. This region corresponds to high energy absorption as the spaces occupied by the pores are filled by the compressed material. After the plateau region, occurs a gradual increase in stress. This behavior of the stress-strain curve is called densification. At this point, the pore walls touch each other, providing greater tensile strength. As the linear elastic region is difficult to identify, is likely to occur buckling and collapse of the pores at the same time. Similar profiles were found by Fook (2012), Wan et al. (2008) and Zhu et al. (2014) [23] [25] [26].

The mechanical properties of porous scaffolds not only depend on the type of material to be used in fabrication, but also are directly related to microstructure, porosity and pore size and how these pores are distributed throughout the scaffold microstructure. In particular, high porosity, which is desired to facilitate cell infiltration and growth of new tissue, results in a reduction of mechanical properties. The scaffolds showed a 55\%, mean porosity and it may be one of the factors are directly influencing the mechanical strength obtained, since it tends to increase the flexure of the walls of the pores and thus instability during the test 
compression. Should be emphasized is the fact that all samples submitted to test remain resistant and suffered no break during, mainly due to the almost amorphous character of the constituents. The mechanical properties of the scaffolds can be improved by introducing crosslinks or ceramic composites [10] [27].

Considering the appropriate mechanical properties, we can state that chitosan scaffolds have a disadvantage when used for support in tissue engineering because these scaffolds are very brittle; that is, they have low mechanical resistance.

\subsection{Cytotoxicity}

The cytotoxicity of chitosan scaffolds were shown in Figure 4. Cell viability was assessed using the MTT reduction method. When looking at the plot the cellular metabolic activity for the scaffolds showed values above $80 \%$, and statistically ( $p$ $<0.05$ ), no significant differences. Thus, it can be considered that no sample showed cytotoxic character in contact with macrophages. This allows us to state that none of the chitosan scaffolds released any toxic products when in contact with the cells.

\section{Conclusion}

The method of ionotropic gelation with tripolyphosphate developed in this study allowed an improvement in the preparation of scaffolds. The results were promising, as the method of particle aggregation samples providing good stability conditions as well as the use of the gelatin to improve the processing and final shape of the scaffolds. Another important factor was the high porosity of the scaffolds, adding thus more optimal parameter when applied in tissue engineering and also drug delivery. The scattering in particle and pore size, aggregated in the presence of gelatin, directly influence the mechanical behavior of the scaffolds. The methodology developed indicates an important alternative to the in vitro

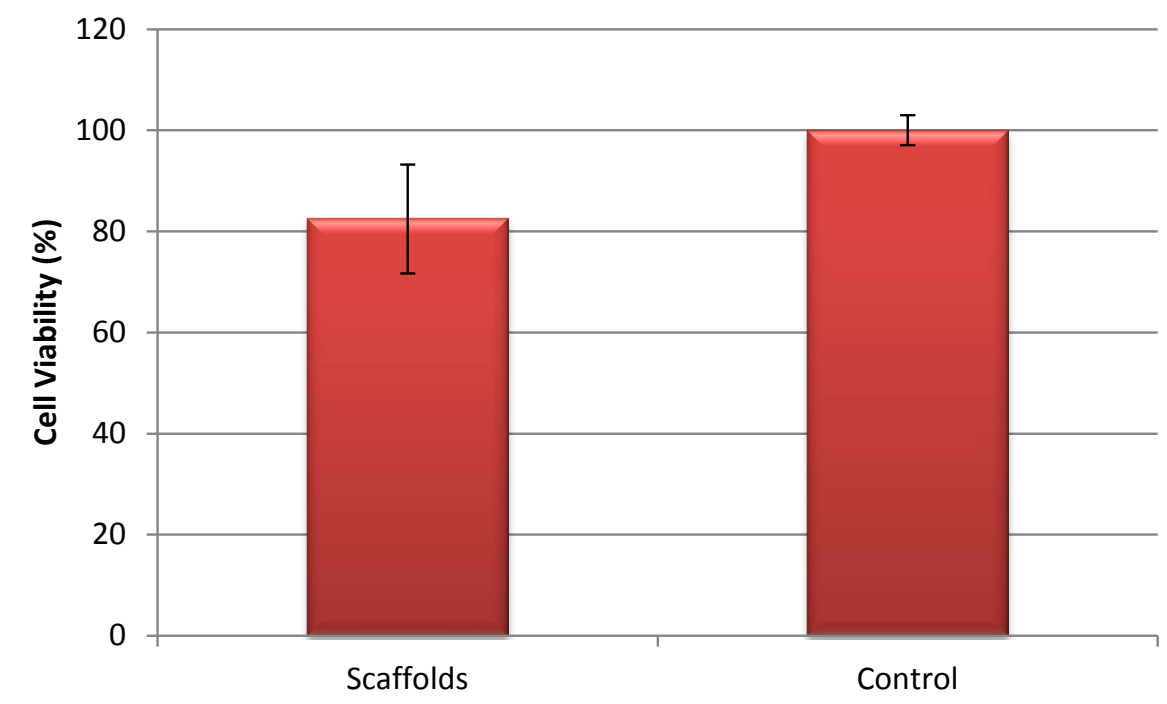

Figure 4. The cytotoxicity of chitosan scaffolds. 
culture of cells, as consequence of the microstructure in the produced scaffolds $\%$. In general, this work offered a new chitosan scaffolds fabrication methodology, producing three-dimensional materials satisfactorily, with a simple strategy based on the application of an adhesive to obtain the chitosan scaffolds. Thus, these novel produced scaffolds can be used in various biomedical applications, such as grafts, a carrier for controlled drug release system and scaffolds for tissue engineering.

One drawback of microsphere scaffolds is the low level of overall porosity, where the variation of porosity, which lies between $40 \%$ and $60 \%$, compared to $>90 \%$ exhibited by scaffolds prepared via. Considering the appropriate mechanical properties, we can state that chitosan scaffolds have a disadvantage when used for support in tissue engineering because these scaffolds are very brittle; that is, they have low mechanical resistance.

The research described in this work described several aspects regarding the production of chitosan scaffolds, highlighting three main points: properties of the produced material, morphological characteristics and three-dimensional structure. In general, the present work offered a new methodology for the manufacture of chitosan scaffolds, producing satisfactory three-dimensional materials with a simple strategy based on the application of an adhesive material to obtain chitosan scaffolds. With this, the produced scaffolds are allowed to be used in various biomedical applications, for example, grafts, dressings, carrier for a controlled drug delivery system and scaffolds for tissue engineering.

\section{Acknowledgements}

The financial support from Coordenação de Aperfeiçoamento de Pessoal de Nível Superior/CAPES and Brazilian Ministry of Health are gratefully acknowledged.

\section{Conflict of Interest}

The authors declared no conflict of interest.

\section{References}

[1] Wang, C., Li, J. and Yao, F. (2012) Application of Chitosan-Based Biomaterials in Tissue Engineering. In: Yao, K., Li, J., Yao, F. and Yin, Y., Chitosan-Based Hydrogels Functions and Applications, CRC Press, Boca Raton.

[2] Correlo, V.M., Gomes, M.E., Tuzlakoglu, K., Oliveira, J.M., Malafaya, P.B., Mano, J.F. and Neves, N.M. (2007) Tissue Engineering Using Natural Polymers. In: Jenkins, M., Ed., Biomedical Polymers, CRC Press, Boca Raton. https://doi.org/10.1533/9781845693640.197

[3] Fideles, T.B., Furtado, G.T.F.S., Lima, D.B., Borges, S.M.P., Pinheiro, I.M.F. and Fook, M.V.L. (2013) Evaluation of Ionic Crosslinked Chitosan Scaffolds for Biomedical Applications. Journal of Chitin and Chitosan Science, 1, 1-7.

https://doi.org/10.1166/jcc.2013.1032

[4] Dhandayuthapanin, B., Yoshida, Y., Maekawa, T. and Kumar, D.S. (2011) Polymer- 
ic Scaffolds in Tissue Engineering Application: A Review. International Journal of Polymer Science, Article ID: 290602, 19.

[5] Thein-Han, W.W. and Misra, R.D.K. (2009) Biomimetic Chitosan-Nanohydroxyapatite Composites Scaffolds for Bone Tissue Engineering. Acta Biomaterialia, 5, 1182-1197. https://doi.org/10.1016/j.actbio.2008.11.025

[6] Wang, T., Zhu, X., Xue, X., and Wu, D. (2012) Hydrogel Sheets of Chitosan, Honey and Gelatin as Burn Wound Dressing. Carbohydrate Polymers, 88, 75-83. https://doi.org/10.1016/j.carbpol.2011.11.069

[7] Croisier, F. and Jérôme, C. (2013) Chitosan-Based Biomaterials for Tissue Engineering. European Polymer Journal, 49, 780-792.

https://doi.org/10.1016/j.eurpolymj.2012.12.009

[8] Jiang, T., Deng, M., James, R., Nair, L. and Laurencin, C.T. (2014) Micro- and Nanofabrication of Chitosan Structures for Regenerative Medicine. Acta Biomaterialia, 10, 1632-1645. https://doi.org/10.1016/j.actbio.2013.07.003

[9] Gorczyca, G., Tylingo, R., Szweda, P., Augustin, E., Sadowska, M. and Milewski, S. (2014) Preparation and Characterization of Genipin Cross-Linked Porous Chitosan-Collagen-Gelatin Scaffolds Using Chitosan- $\mathrm{CO}_{2}$ Solution. Carbohydrate Polymers, 102, 901-911. https://doi.org/10.1016/j.carbpol.2013.10.060

[10] Malafaya, P.B., Pedro, A.J., Peterbauer, A., Gabriel, C., Red, H. and Reis, R.L. (2005) Chitosan Particles Agglomerated Scaffolds for Cartilage and Osteochondral Tissue Engineering Approaches with Adipose Tissue Derived Stem Cells. Journal of Materials Science: Materials in Medicine, 16, 1077-1085.

https://doi.org/10.1007/s10856-005-4709-4

[11] Cruz, D.M.G., Ivirico, J.L.E., Gomes, M.M., Ribelles, J.L.G., Sanches, M.S., Reis, R.L. and Mano, J.F. (2008) Chitosan Microparticles as Injectable Scaffolds for Tissue Engineering. Journal of Tissue Engineering and Regenerative Medicine, 2, 378-380. https://doi.org/10.1002/term.106

[12] Gomes, M.E., Malafaya, P.B. and Reis, R.L. (2005) Fiber Bonding and Particle Aggregation as Promising Methodologies for the Fabrication of Biodegradable Scaffolds for Hard-Tissue Engineering. In: Reis, R.L. and Román, J.S., Eds., Biodegradable Systems in Tissue Engineering and Regenerative Medicine. CRC Press, Boca Raton.

[13] Miranda, E.S., Silva, T.H., Reis, R.L. and Mano, J.F. (2011) Nanostructured Natural-Based Polyelectrolyte Multilayers to Agglomerate Chitosan Particles into Scaffolds for Tissue Engineering. Tissue Engineering: Part A, 17, 2663-2674. https://doi.org/10.1089/ten.tea.2010.0635

[14] Hsieh, W., Chang, C. and Lin, S. (2007) Morphology and Characterization of 3D Micro-Porous Structured Chitosan Scaffolds for Tissue Engineering. Colloids and Surfaces: Biointerfaces, 57, 250-255. https://doi.org/10.1016/j.colsurfb.2007.02.004

[15] Jiang, T., Abdel-Fattah, W.I. and Laurencin, C.T. (2006) In vitro Evaluation of chitosan/poly(lactic acid-glycolic acid) Sintered Microsphere Scaffolds for Bone Tissue Engineering. Biomaterials, 27, 4894-4903. https://doi.org/10.1016/j.biomaterials.2006.05.025

[16] Borden, M., Attawia, M., Khan, Y. and Laurencin, C.T. (2002) Tissue Engineered Microsphere-Based Matrices for Bone Repair: Design and Evaluation. Biomaterials, 23, 551-559. https://doi.org/10.1016/S0142-9612(01)00137-5

[17] Kucharska, M., Walenko, K., Lewandowska-Szumieł, M., Brynk, T., Jaroszewicz, J. and Ciach, T. (2015) Chitosan and Composite Microsphere-Based Scaffold for Bone Tissue Engineering: Evaluation of Tricalcium Phosphate Content Influence on 
Physical and Biological Properties. Journal of Materials Science: Materials in Medicine, 26, 1-12. https://doi.org/10.1007/s10856-015-5464-9

[18] Silva, S.S., Duarte, A.R.C., Mano, J.F. and Reis, R.L. (2013) Design and Functionalization of Chitin-Based Microsphere Scaffolds. Green Chemistry, 15, 3252-3258.

https://doi.org/10.1039/c3gc41060a

[19] Fideles, T.B., Barbosa, W.T., Lima, D.B., Borges, S., Trindade, L.C., Silva, P.C.D., Pinheiro, Í.M.F. and Fook, M.V.L. (2015) Evaluation of Chitosan Scaffolds Produced by Particle Aggregation Method for Biomedical Applications. Journal of Chitin and Chitosan Science, 3, 32-38. https://doi.org/10.1166/jcc.2015.1091

[20] Kucharska, M., Walenko, K., Butruk, B., Brynk, T., Heljak, M. and Lianch, T. (2010) Fabrication and Characterization of Chitosan Microspheres Agglomerated Scaffolds for Bone Tissue Engineering. Materials Letter, 64, 1059-1062. https://doi.org/10.1016/j.matlet.2010.02.012

[21] Malafaya, P.B., Santos, T.C., Griensven, M.V. and Reis, R.L. (2008) Morphology, Mechanical Characterization and in Vivo Neo-Vascularization of Chitosan Particle Aggregated Scaffolds Architectures. Biomaterials, 29, 3914-3926. https://doi.org/10.1016/j.biomaterials.2008.06.023

[22] Valente, J.F.A., Valente, T.A.M., Alves, P., Ferreira, P., Silva, A. and Correia, I.J. (2012) Alginate Based Scaffolds for Bone Tissue Engineering. Materials Science and Engineering: C, 32, 2596-603. https://doi.org/10.1016/j.msec.2012.08.001

[23] Wan, Y., Wu, H., Cao, X. and Dalai, S. (2008) Compressive Mechanical Properties and Biodegradability of Porous Poly (Caprolactone)/Chitosan Scaffolds. Polymer Degradation and Stability, 93, 1736-1741.

https://doi.org/10.1016/j.polymdegradstab.2008.08.001

[24] Yao, C., Liao, J., Chung, C., Sung, W. and Chang, N. (2012) Porous Chitosan Scaffolds Cross-Linked and Nature Procedure Applied to Investigate Cell Regeneration. Applied Surface Science, 262, 218-221. https://doi.org/10.1016/j.apsusc.2012.05.128

[25] Fook, A.C.B.M. (2012) Desenvolvimento de Arcabouços Compósitos Hidroxiapatita-Biopolímero para Engenharia de Tecidos. Tese (Doutorado em Ciência e Engenharia de Materiais). Universidade Federal de Campina Grande. Campina Grande.

[26] Zhu, Y., Wan, Y., Zhan, J., Yin, D. and Cheng, W. (2014) Manufacture of Layered Collagen/Chitosan-Polycaprolactone Scaffolds with Biomimetic Microarchitecture. Collois and Surfaces B: Biointerfaces, 113, 352-360. https://doi.org/10.1016/j.colsurfb.2013.09.028

[27] Salermo, A. and Netti, P.A. (2014) Optimal Design and Manufacture of Biomedical Foam Pore Structure for Tissue Engineering. In: Netti, P.A., Ed., Biomedical Foams for Tissue Engineering Applications, Elsevier, Amsterdam. https://doi.org/10.1533/9780857097033.1.71 